\title{
Convergence of stem cell behaviors and genetic regulation between animals and plants: insights from the Arabidopsis thaliana stomatal lineage
}

\author{
Juliana L. Matos ${ }^{2}$ and Dominique C. Bergmann ${ }^{1,2 *}$
}

Addresses: ${ }^{1}$ Howard Hughes Medical Institute and ${ }^{2}$ Department of Biology, 371 Serra Mall, Stanford University, Stanford, CA 94305, USA

*Corresponding author: Dominique C. Bergmann (dbergmann@stanford.edu)

Fl000Prime Reports 2014, 6:53 (doi:10.12703/P6-53)

All F1000Prime Reports articles are distributed under the terms of the Creative Commons Attribution-Non Commercial License (http://creativecommons.org/licenses/by-nc/3.0/legalcode), which permits non-commercial use, distribution, and reproduction in any medium, provided the original work is properly cited.

The electronic version of this article is the complete one and can be found at:http://f $1000 . c o m / p r i m e / r e p o r t s / b / 6 / 53$

\begin{abstract}
Plants and animals are two successful, but vastly different, forms of complex multicellular life. In the 1600 million years since they shared a common unicellular ancestor, representatives of these kingdoms have had ample time to devise unique strategies for building and maintaining themselves, yet they have both developed self-renewing stem cell populations. Using the cellular behaviors and the genetic control of stomatal lineage of Arabidopsis as a focal point, we find current data suggests convergence of stem cell regulation at developmental and molecular levels. Comparative studies between evolutionary distant groups, therefore, have the power to reveal the logic behind stem cell behaviors and benefit both human regenerative medicine and plant biomass production.
\end{abstract}

\section{Introduction and context}

Multicellularity evolved independently in animals and plants, yet both groups establish stem cell populations during embryogenesis and rely on the maintenance and activity of these populations into adulthood [1-3]. Stem cells are uncommitted cells with the competence to selfrenew and to produce specialized cells, tissues and organs. Execution of these tasks requires coordination between stem-cell intrinsic and extrinsic factors. Depletion or malfunction of stem cells leads to impaired organ growth or tissue repair, while uncontrolled division leads to tumor formation. Despite independent evolutionary origins, the developmental biology of animal and plant stem cells displays astonishing similarities.

In this review we will briefly describe the ontogeny and characteristics of stem cell populations in animals and plants, and then focus on the stem cell properties of the stomatal lineage in Arabidopsis thaliana. Stomata are specialized structures in the plant leaf epidermis formed by two cells (the guard cells) that open and close to allow the exchange of gases between the plant and the atmosphere. Stomata are derived from a population of stem cells dispersed on the epidermis that undergo asymmetric self-renewing cell divisions before stably differentiating into guard cells. The number and orientation of asymmetric divisions is regulated by cell-autonomous mechanisms, as well as by communication with neighbor cells and integration of environmental cues [4,5]. Bound by immobile cell walls, stomatal lineage cells leave a record of their fate and division history in their spatial arrangement on the leaf surface; thus they provide a unique opportunity to dissect how stem cell division and fate activities progress in vivo. By comparing the initiation, progression and termination of the stomatal lineage to other stem-cell lineages at both cellular and molecular levels, we hope to illustrate the utility (and limitations) of this system among plant and animal stem cell models.

\section{Stem cell populations in animals}

In mammalian development, stem cell potency is progressively restricted. Pluripotent embryonic stem cells can generate any somatic or germline cell type but not extra-embryonic tissues [6]. Embryonic stem cells undergo further specification to establish germ line stem cells and the lineage-specific stem cells that will generate particular 
tissues and organs [7] (Figure 1a). Associated with most organs are adult stem cells that persist throughout life and play an important role in tissue repair [7-9] (Figure 1a). When compared to the embryonic stem cells, adult stem cells have a lessened capacity to proliferate and produce a narrower range of terminal cell identities [9]. The extent to which adult stem cells contribute to tissue homeostasis varies: they continuously produce cells in the blood, skin, and gastrointestinal systems, or are mostly quiescent such as in the muscle, brain, and liver [10]. The niche gives the structural and molecular support necessary to maintain adult stem cells and relies heavily on autocrine signals from stem cells and progeny, and paracrine signals from neighbor cells, as well as long-distance cues for instructions to activate stem cells or keep them quiescent [10] (Figure $1 \mathrm{a}$, green). When activated, stem cells give rise to a few proliferating progenitor cells. The progenitor cells undergo limited rounds of transit-amplifying divisions and then terminally differentiate, losing the ability to proliferate further [11]. During aging, biasing or depletion of stem cell activity is as likely due to defects in the niche as it is to loss of capacity in the stem cells themselves. Once lost, niches and the stem cells within them cannot be replaced $[12,13]$ (Figure 1a, red). The origin of most adult stem cells is still poorly understood. Among the best characterized (muscle, blood, and neural lineages), the general view is that adult stem cells arise from a subpopulation of embryonically specified somatic lineage cells that colonize specific niches that will maintain their self-renewing activity and restrict their fate to a given lineage [14] (Figure 1a).

The differentiation process in human cells was considered irreversible until breakthrough work by Takahashi and Yamanaka [15] showing somatic cells reprogrammed into

Figure I. Distinct features of stem cell populations in mammals (a) and plants (b)
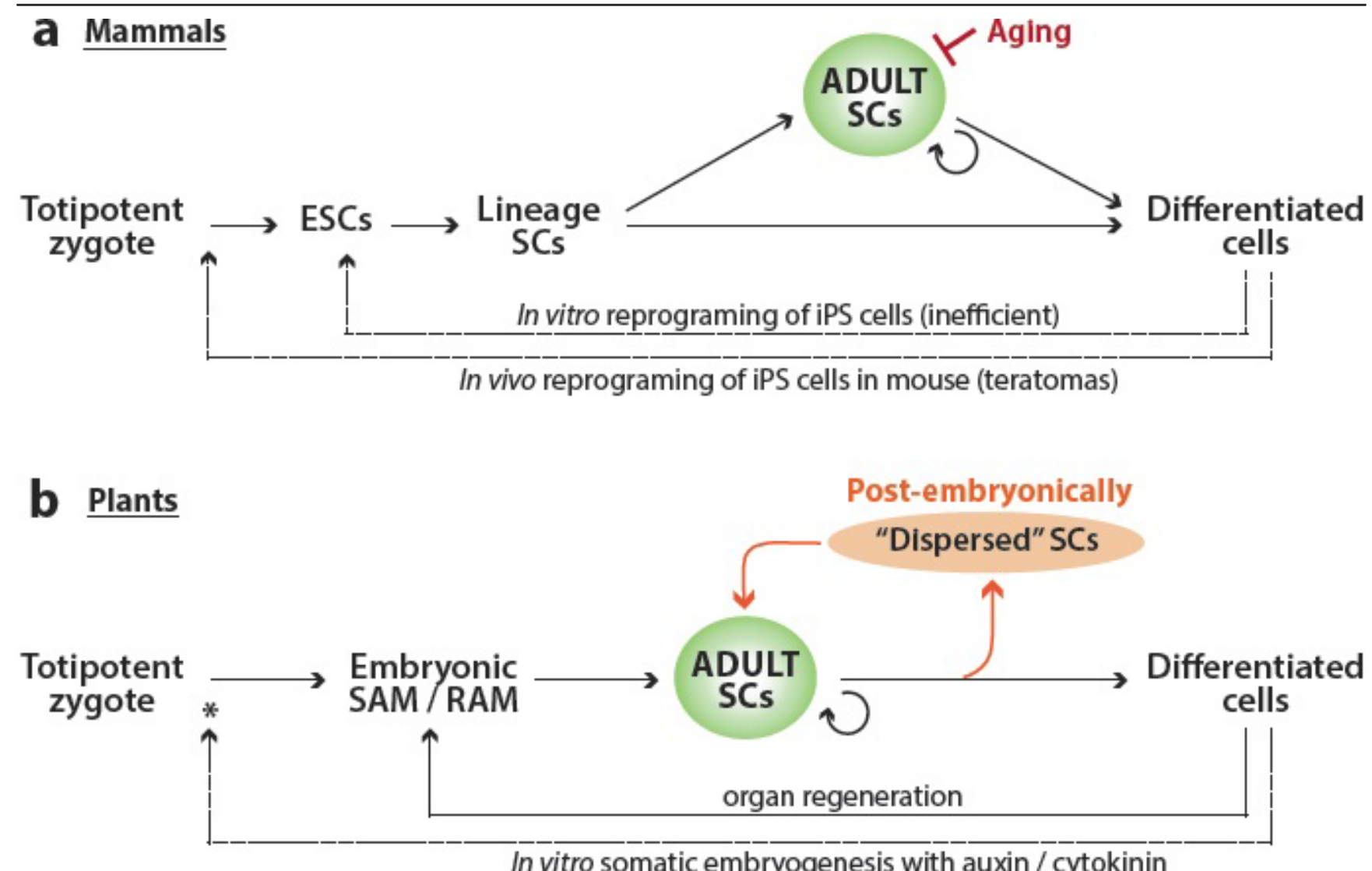

Progression from totipotent to differentiated cells (left to right). Adult stem cells (SCs) contribute to tissue repair in mammals, but in plants generate entire new organs throughout the lifespan. The niche supports adult SCs (green), and in mammals, niche activity declines with age (red). Plants generate adult SCs such as the cambium and stomatal and lateral root precursors (orange) that build additional organs postembryonically and regenerate damaged organs by de novo specification of meristems.

* In plants, in vitro somatic embryogenesis regenerates a complete new organism (dashed arrows), but whether extra-embryonic tissues are also regenerated by this treatment has not been tested extensively. ESC, embryonic stem cell; iPS, induced pluripotent stem cell; RAM, root apical meristem; SAM, shoot apical meristem. 
embryonic stem cells in vitro by overexpression of four transcription factors: Oct4, Klf4, Sox2 and c-Myc; recently, these four factors were also shown to reprogram mouse cells in vivo (though with accompanying teratomas) [16] (Figure 1a, dashed arrows). Animal cell reprogramming is still inefficient, so improvements in reprogramming somatic cells to pluripotent or totipotent stem cells, together with efficient and reliable protocols for differentiation of specific cell types are sought for regenerative medicine [17-21].

\section{Stem cell populations in plants}

When compared to animals, plants exhibit greater flexibility in cellular reprograming and organ (re)generation. Entire plants can be regenerated following in vitro reprogramming of somatic cells by treatments with the hormones auxin and cytokinin, a process described more than 50 years ago [22] (Figure 1b, dashed arrow). Despite the ease with which they can be reprogrammed and regenerated, plants normally follow stereotyped stem cell transitions (Figure 1b). Pluripotent stem cell populations of the shoot and root apical meristems (SAM and RAM) generate all above- and below-ground organs, respectively $[23,24]$. The embryonically established SAM and RAM play a much more active role in the postembryonic life of the plant than stem cells do in animals; rather than being a reservoir for repair of largely static tissues, plant meristems are the continuous source of new cells, tissues and organs. Herein, we will refer to stem cells in the adult meristems as adult stem cells (Figure 1b, Adult SCs). The niches associated with the SAM and RAM both maintain selfrenewing activity and prevent differentiation for extended periods of time, but they have distinct cellular organization and signaling processes [25-27] (Figure 1b, green). The dome-shaped SAM contains slowly dividing stem cells in its center and more rapidly dividing cells towards the periphery [28]. There are meristem-to-organ gradients of gene expression programs tied to the establishment of new organs and cells pushed away from the center of the SAM (via division and growth, as plant cell walls prevent cell migration) become susceptible to signals that stimulate organ identity and development [28]. The RAM is an organized collection of lineage-specific stem cells (known as initial cells) surrounding the quiescent center cells, which serve as a niche to maintain the initial cells [29]. Initial cells give rise to specific cell types (e.g. vasculature, endodermis, cortex, epidermis and lateral root cap) arranged in continuous files [30,31]. As in the SAM, when divisions in the files push older daughter cells away from the niche, these daughters are exposed to signals that promote differentiation [32-35].

"Dispersed" stem cell populations also elaborate the plant body plan (Figure $1 \mathrm{~b}$, orange). Lateral roots are initiated through postembryonic divisions of the pericycle (a vascular initial-derived lineage). Although the pericycle cells that initiate a lateral root may have been "primed" in the RAM, they only begin their divisions at some distance from this niche and are then capable of generating all of the tissues of a root, including new initials and a stem cell niche [36,37]. Similarly, axial meristems derived from the SAM can initiate lateral branches containing the same cell types as the primary shoot [38]. More limited in the cell types they can generate are the cambium, a long-lived meristem derived from the vascular initials that contributes to radial growth (as in the thickening of tree trunks) by dividing to produce xylem and phloem cells [39], and the stomatal lineage of the leaf epidermis, which gives rise to two differentiated cell types, stomatal guard cells and pavement cells. Stomatal lineage stem cells, like animal adult stem cells, cambium and lateral root precursors, proliferate and regenerate within tissues that are mostly terminally differentiated. In contrast to these other populations, the stomatal lineage is exclusively post-embryonic in origin, and cannot be traced back to founder cells in the shoot or root meristems. How is this de novo stem cell specification regulated?

\section{Stem cell properties of the stomatal lineage}

A stomatal lineage is established by asymmetric divisions of a meristemoid mother cell (MMC) into a meristemoid (M, smaller daughter) and stomatal lineage ground cell (SLGC, larger daughter - Figure 2a, green). The placement and number of MMCs of a leaf surface is not predetermined, and MMCs produce more MMCs through a bifurcating lineage in which meristemoids can recreate themselves (thus, by definition also being MMCs amplifying division, Figure 2a). Additionally, SLGCs can execute a specifically oriented asymmetric division (spacing division, Figure 2a) to produce another meristemoid and SLGC. These amplifying and spacing divisions continue for several rounds, creating cells that contribute to the overall growth of the leaf (Figure 2a, blue), but eventually meristemoids will convert into guard mother cells (GMCs) that undergo exactly one symmetric division to become guard cells (Figure 2a, purple). SLGCs eventually become endoreplicated pavement cells (Figure 2a, white). Each individual stomatal lineage follows intrinsic division rules, but lineages develop alongside each other and thus are also subject to influences from neighbors. How the extensive catalogue of signals and receptors mediate intra and inter-lineage signaling to achieve an appropriate pattern and number of cells is an area of active research [40-42]. For our discussion here we will note only that plants lack many key animal stem cell signaling pathways such as Wnt, Notch and Janus kinase/signal transducers and activators 
Figure 2. Comparative analysis of the transcriptional control in the stomatal (a) and myogenic (b) stem cell populations

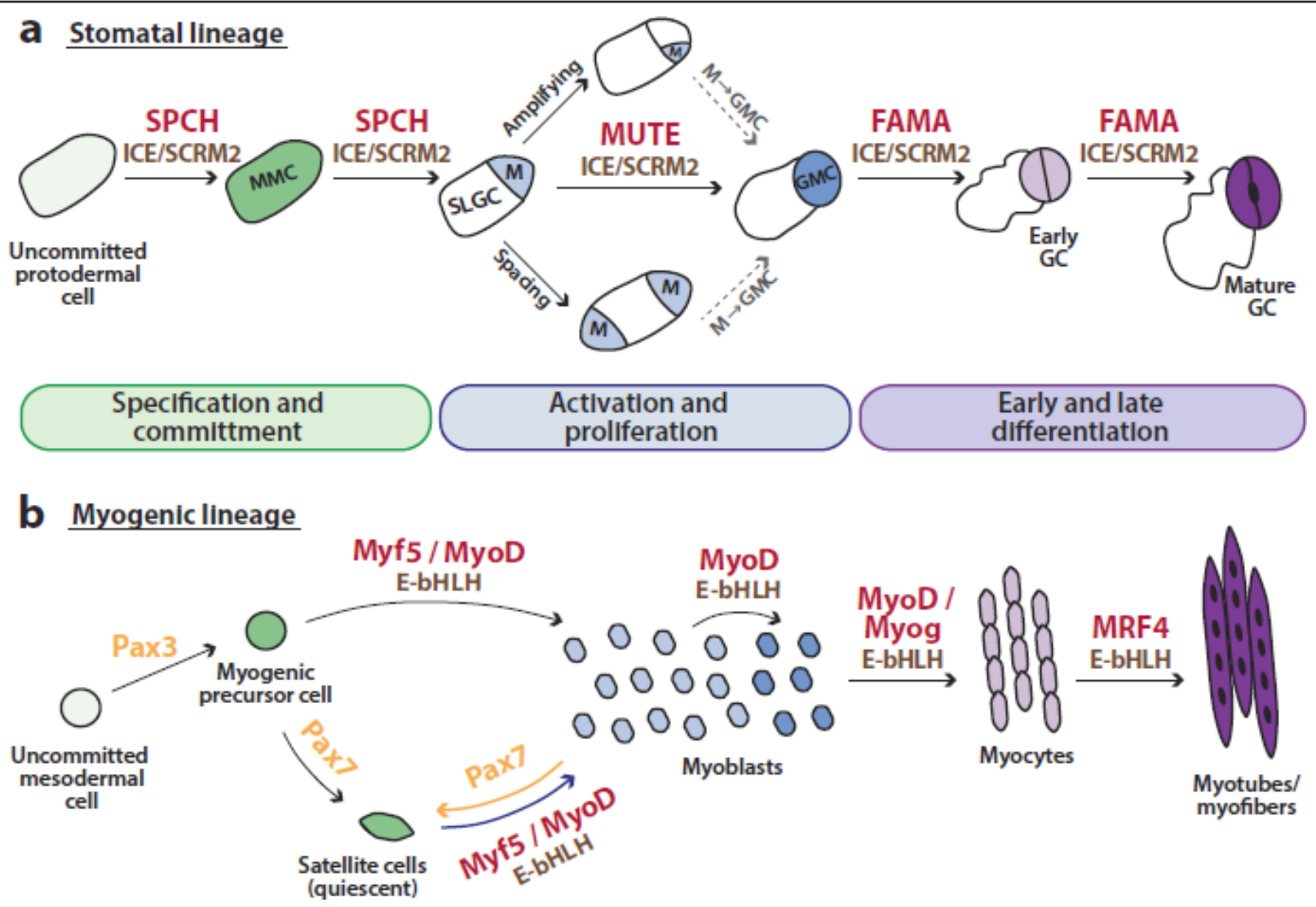

Green, blue and purple colors indicate three stages in the developmental pathways and the cell types assigned to them. Transition between light and dark versions of a color corresponds to initiation and termination of each stage. Lineage specific basic helix-loop-helix (bHLH) transcription factors (red) and their more general bHLH dimerization partners (brown) regulate the major transitions. In the muscle lineage, paired homeobox proteins Pax 3 and 7 (orange) are involved in the specification of myogenic precursor and satellite cells, respectively, and Pax7 can drive the return of myoblasts into a quiescent state to replenish a depleted niche (orange arrow). Activities equivalent to those mediated by Pax3/7 are mediated by SPCH in stomatal development.

GC, guard cell; GMC, guard mother cell; M, meristemoid; Myog, myogenin; SLGC, stomatal lineage ground cell.

of transcription (JAK-STAT) [43,44], but do possess mitogen-activated protein (MAP) kinase signaling components that they, like their animal counterparts, use in stem cell decisions $[45,46]$.

Considering their early divisions, MMCs are like selfrenewing stem cells but, considering their final identity, MMCs are akin to transit amplifying cells that are depleted when they differentiate into guard cells or pavement cells. The dispersed positions and asynchrony of MMC activities (and the intercalation of new MMCs as the organ develops) pose challenges for the concept of a stem cell niche in this system. There is no place for a physical niche structure and signals that promote, repress or orient stem cell divisions are created by the products (daughter cells) of those divisions. Robinson and collaborators [47] redefined a niche in this context after tracking cell behaviors over multiple rounds of division and noticing that many divided three times in a spiral to surround the meristemoid, which would then differentiate into a GMC and later, the guard cells. Here, creation of a physical "niche" of lineally related sisters seems to be the cue to terminate stem cell activity. The bifurcating behavior of MMC daughters would also seem to be at odds with the idea that stem cells divide to recreate themselves and produce a differentiating daughter. Recent studies in mice, however, indicate that the equal number of stem cells and differentiating cells is a population average rather than a result of each stem cell dividing to create a stem cell and differentiating daughter [48]. Thus, it may be fairly common to have stem cell populations where both daughters can be stem cells. Because the stomatal lineage exhibits characteristics typical of stem-cell lineages, but also some differences, it serves as an important counterpoint to re-examine our assumptions about what properties are necessary in a 
self-renewing cell population. This theme of overall similarities, but interesting differences, continues if we examine regulators of stomatal and animal adult stem cells at the molecular level.

Among the four transcription factors used in induced pluripotent stem cell (iPS) reprogramming, Oct4, Klf4, Sox2 and c-Myc, homologues of only c-Myc (a basic helixloop-helix or bHLH domain transcription factor) are present in plants. During reprogramming, the general roles for Oct4, Klf4, and Sox2 are thought to be selecting targets and recruiting RNA Polymerase II [49]. On the other hand, c-Myc is found associated with many genomic regions (both genic and intergenic) and, from these positions, may drive chromatin changes by recruiting histone acetyltransferases and the SWI/SNF complex to help overcome chromatin inaccessibility $[18,49,50]$. In the course of normal plant development, Myc/bHLH proteins regulate stem cell decisions in meristems $[51,52]$ and the vasculature $[53,54]$ as well as in numerous animal stem cell populations (e.g. neural, hematopoietic, cardiomyocyte, intestinal and pancreatic) [55-60]. As most multicellular organisms encode many bHLH proteins, this conserved association with stem cell decisions may not be surprising. What is more striking is the similarity of the larger regulatory networks (in which the bHLHs are embedded) used in the stomatal lineage and in myogenic precursors.

\section{bHLH networks in stomatal and muscle development}

In both muscle cells and the stomatal lineage, closely related bHLH transcription factors drive transitions between the major cell types and share common dimerization partners (Figure 2, red and brown). In the stomatal lineage, group Ia protein SPEECHLESS (SPCH) is required for asymmetric divisions of MMCs that initiate and expand the lineage [61]. SPCH's closest paralog, MUTE, is expressed in late-stage meristemoids and is required to terminate asymmetric divisions and promote differentiation of meristemoids into GMCs [62]. Finally, the next closest paralog, FAMA, drives differentiation of guard cells, while also repressing cell division [63]. Each of these stage-specific bHLHs forms a heterodimer with the more broadly expressed group IIIb bHLHs SCRM/ICE1 and SCRM2 [64] (Figure 2a, ICE/SCRM2). Loss of SPCH or ICE1 and SCRM2 eliminates the stem cell lineage completely, whereas loss of MUTE extends the asymmetric division stage. When overexpressed, MUTE and FAMA can reprogram other epidermal cells into guard cells $[63,64]$.

In skeletal muscle, an evolutionarily distinct clade of closely related bHLHs (Myf5, MyoD, myogenin, and MRF4) regulate embryonic and adult myogenesis, including the activation of stem cells $[65,66]$. Like the stomatal bHLHs, the muscle factors dimerize with a common set of broadly expressed partners (Figure 2b, E-bHLHs) and are expressed in a temporal hierarchy, with MyoD and Myf5 acting earlier to control determination and proliferation of myoblasts, and myogenin and MRF4 being associated with terminal differentiation of myofibers [67]. Expression of Myf5 and MyoD (Figure 2b, green) initiates the myogenic program leading to the development and renewal of myoblasts, an intermediate cell type capable of extensive proliferation (Figure 2b, blue). Myoblasts convert into myocytes, which then express myogenin and fuse to form myofibers, which continue to express the terminal differentiation regulator MRF4 (Figure 2b, purple).

Muscle and stomatal development differ in the initiation step; in the case of stomata, SPCH expression is sufficient to generate and maintain all stem cell-like precursors. In muscle, the animal-specific Pax gene family is required to select myogenic precursor cells (Pax3) and to regulate transitions between myoblasts and adult muscle stem cells (Pax7 - Figure 2b, orange). Some Pax7-expressing cells are found near the myofibers but are destined to be quiescent throughout embryogenesis. These so-called "satellite cells" are maintained by a specific niche and exhibit limited or no gene expression, protein synthesis or cell division. Upon injury or exercise, however, satellite cells upregulate Pax7 and subsequently Myf5 and MyoD, thus entering the same pathway as embryonic cells did on their way to forming myofibers $[67,68]$ (Figure $2 b$, blue arrow).

\section{bHLH transcription factors as regulators of stem cell populations}

Why might suites of bHLHs have been independently recruited for skeletal myogenesis and stomatal development? One hypothesis is that the intrinsic structure of bHLHs - their capacity to interact with DNA, with other bHLHs or with other protein complexes - is well suited to developmental/stem cell roles. The binding site associated with bHLHs is the E-box (CANNTG), a sequence found many thousands of times in a typical genome, allowing bHLHs to access promoters, enhancers and non-genic regions. The purported role of c-Myc as a general transcriptional activator in reprogramming is consistent with a wide distribution of its binding sites and with its capacity to recruit chromatin modifiers. The same theme emerges in specific lineages; for example, MyoD recruits the SWI/SNF ATP-dependent chromatin remodeling complex and p300 histone acetyltransferase to establish open chromatin structure for muscle gene activation $[69,70]$. Less is known in plants, but bHLHs have been associated with SWI/SNF components [71], and disruption of chromatin regulators results in defects in meristematic activity [72-75]. 
The heterodimerization capacity (and, in the case of the stomatal bHLHs, requirement) of bHLHs also contributes to their suitability for developmental decisions. Titrating a common dimerization partner can ensure that transitions are made cleanly, as production of one heterodimer limits the ability of a different heterodimer to form, and the sequential activation of bHLHs by previous ones allows development to proceed unidirectionally. Again looking at myogenesis, MyoD induces expression of myogenin, which in turns represses Myf5 and activates MRF4 $[67,76]$. So far, studies with the stomatal bHLHs suggest that SPCH, MUTE and FAMA form obligate heterodimers with ICE1/SCRM and SCRM2, but not among themselves, and ongoing studies of the dynamics of these proteins are likely to yield interesting results. Does $\mathrm{SPCH}$, for example, induce the expression of MUTE and MUTE of FAMA? Or might there even be feedback regulation of the later genes in the pathway regulating the earlier ones?

A second hypothesis for why related bHLHs regulate sequential steps in development and regeneration comes from observations that gene duplications and developmental complexity often parallel each other [77]. In stomatal development, there is a correspondence between the number of discrete steps in the pathway to make stomata and the number of group Ia bHLHs, with the FAMA-driven differentiation function most likely the ancestral function and the asymmetric-division promoting activity of SPCH being a later addition $[78,79]$. The four myogenic regulatory factors (Myf5, MyoD, myogenin, and MRF4) arose from vertebrate-specific duplications [80,81]. The invertebrates Caenorhabditis elegans and Drosophila have single MyoD orthologs and relatively simple muscle lineages, with Drosophila not maintaining stem cells in adults and C. elegans lacking stem cells altogether [82]. As with stomatal development, MyoD duplications may have provided an opportunity to build flexibility and regenerative capacities within a defined cell-type lineage.

\section{Conclusion}

The stem cell field has been enriched by taking into account natural diversity in regenerative capacity, using, for example, amphibians as a model for limb regeneration and planaria as models for cellular totipotency [83]. The stomatal lineage provides yet another model with complementary utilities for the field. The postembryonic initiation of multiple stomatal lineages on organ surfaces make it experimentally accessible in ways that internal, embryonically-derived, lineages are not. Moreover, because plant cells do not move, stomatal lineage stem cells leave a permanent record of all past divisions in the arrangement of cells around them. This feature can be exploited to monitor not only normal development, but responses to reprogramming cues. The remarkable similarities in the common logic and use of related bHLH transcription factors between stomatal and muscle (and some neural) situations could be leveraged to investigate constraints on gene regulatory networks embedded in complex systems, and, because forward genetic screens are feasible in Arabidopsis, to identify new regulators that might contribute to bHLH networks in animal systems.

\section{Abbreviations}

bHLH, basic helix-loop-helix; GMC, guard mother cell; iPS, induced pluripotent stem cell; MMC, meristemoid mother cell; RAM, root apical meristem; SAM, shoot apical meristem; SLGC, stomatal lineage ground cell; SPCH, SPEECHLESS.

\section{Disclosures}

The authors declare that they have no disclosures.

\section{Acknowledgements}

We thank members of the lab for comments on the manuscript and apologize to colleagues whose work we could not cite due to length restrictions. Work on stem cells in our laboratory is funded by US National Institutes of Health R01GM086632-01. Juliana L. Matos is supported by the Charles Yanofsky Graduate Fellowship. Dominique C. Bergmann is a Gordon and Betty Moore Foundation Investigator of the Howard Hughes Medical Institute.

\section{References}

I. Meyerowitz EM: Plants Compared to Animals: The Broadest Comparative Study of Development. Science 2002, 295:|482-5.

2. Sablowski R: Plant and animal stem cells: conceptually similar, molecularly distinct? Trends Cell Biol 2004, I4:605-I I.

3. Niklas KJ, Newman SA: The origins of multicellular organisms. Evol Dev 2013, 15:41-52.

\section{FlOOOPrime} RECOMMENDED

4. Bergmann DC, Sack FD: Stomatal Development. Annu Rev Plant Biol 2007, 58: |63-8I.

5. Pillitteri LJ, Dong J: Stomatal Development in Arabidopsis. Arab Book 2013, II:e0162.

6. Rossant J: Stem Cells and Early Lineage Development. Cell 2008, I32:527-31.

7. Young HE, Black AC: Adult stem cells. Anat Rec 2003, 276A:75- 102.

8. Wagers AJ, Weissman IL: Plasticity of adult stem cells. Cell 2004, I 1 6:639-48.

9. Alison MR, Islam S: Attributes of adult stem cells. J Pathol 2009, 2 I 7: |44-60.

10. Rezza A, Sennett R, Rendl M: Adult stem cell niches: cellular and molecular components. Curr Top Dev Biol 2014, 107:333-72.

II. Clarke MF, Fuller M: Stem Cells and Cancer: Two Faces of Eve. Cell 2006, I 24: I I II-5.

12. Rando TA: Stem cells, ageing and the quest for immortality. Nature 2006, 44I: 1080-6.

13. Mahmoudi S, Brunet A: Aging and reprogramming: a two-way street. Curr Opin Cell Biol 2012:744-56. 
14. Melton D: "Stemness": Definitions, Criteria, and Standards. In Essentials of Stem Cell Biology. Volume I. 3rd edition. Edited by Lanza R, Atala A. Elsevier Inc; 2014:5-12.

15. Takahashi K, Yamanaka S: Induction of Pluripotent Stem Cells from Mouse Embryonic and Adult Fibroblast Cultures by Defined Factors. Cell 2006, I 26:663-76.

\section{FlOOOPrime}

16. Abad M, Mosteiro L, Pantoja C, Cañamero M, Rayon T, Ors I, Graña O, Megías D, Domínguez O, Martínez D, Manzanares M, Ortega S, Serrano M: Reprogramming in vivo produces teratomas and iPS cells with totipotency features. Nature 2013, 502:340-5.

\section{FlOOOPrime} RECOMMENDED

17. Yamanaka S: Induced Pluripotent Stem Cells: Past, Present, and Future. STEM 2012, 10:678-84.

18. Apostolou E, Hochedlinger K: Chromatin dynamics during cellular reprogramming. Nature 2013, 502:462-7I.

19. De Los Angeles A, Daley GQ: Stem cells: Reprogramming in situ. Nature 2013, 502:309-I0.

20. Xia Y, Nivet E, Sancho-Martinez I, Gallegos T, Suzuki K, Okamura D, Wu M-Z, Dubova I, Esteban CR, Montserrat N, Campistol JM, Belmonte JCl: Directed differentiation of human pluripotent cells to ureteric bud kidney progenitor-like cells. Nature 2013 , | $5:$ : $507-15$

\section{FIOOOPrime RECOMMENDED}

21. Inoue $H$, Nagata $N$, Kurokawa $H$, Yamanaka S: iPS cells: a game changer for future medicine. The EMBO Journal 2014, 33:409-17.

22. SKOOG F, MILLER CO: Chemical regulation of growth and organ formation in plant tissues cultured in vitro. Symp Soc Exp Biol 1957, I I: I I8-30.

23. Weigel D, Jürgens G: Stem cells that make stems. Nature 2002, 4I5:75I-4.

24. Stahl $Y$, Simon R: Plant primary meristems: shared functions and regulatory mechanisms. Curr Opin Plant Biol 2010, 13:53-8.

25. Byrne ME, Kidner CA, Martienssen RA: Plant stem cells: divergent pathways and common themes in shoots and roots. Curr Opin Genetics Develop 2003, 13:551-7.

26. Scheres B: Stem-cell niches: nursery rhymes across kingdoms. Nat Rev Mol Cell Biol 2007, 8:345-54.

27. Dinneny JR, Benfey PN: Plant Stem Cell Niches: Standing the Test of Time. Cell 2008, I32:553-7.

28. Žádníková P, Simon R: How boundaries control plant development. Curr Opin Plant Biol 2014, I7:1 16-25.

29. van den Berg C, Willemsen V, Hage W, Weisbeek P, Scheres B: Cell fate in the Arabidopsis root meristem determined by directional signalling. Nature 1995, 378:62-5.

30. Jiang K, Feldman LJ: Regulation of root apical meristem development. Annu Rev Cell Dev Biol 2005, 21:485-509.

31. Bennett T, Scheres B: Root development-two meristems for the price of one? Curr Top Dev Biol 2010, 91:67-102.

32. Sarkar AK, Luijten M, Miyashima S, Lenhard M, Hashimoto T, Nakajima K, Scheres B, Heidstra R, Laux T: Conserved factors regulate signalling in Arabidopsis thaliana shoot and root stem cell organizers. Nature 2007, 446:8I I-4.

33. Busch W, Benfey PN: Information processing without brains - the power of intercellular regulators in plants. Development 2010, 137:1215-26.

34. Sablowski R: Plant stem cell niches: from signalling to execution. Curr Opin Plant Biol 20I I, I 4:4-9.

35. Aichinger E, Kornet N, Friedrich T, Laux T: Plant Stem Cell Niches. Annu Rev Plant Biol 2012, 63:6I5-36.

36. Lavenus ], Goh T, Roberts I, Guyomarc'h S, Lucas M, De Smet I, Fukaki H, Beeckman $T$, Bennett $M$, Laplaze L: Lateral root development in Arabidopsis: fifty shades of auxin. Trends Plant Sci 20I3, 18:450-8.
37. Miyashima S, Sebastian J, Lee J-Y, Helariutta Y: Stem cell function during plant vascular development. The EMBO Journal 20I2, 32:178-93.

38. Barton MK: Twenty years on: The inner workings of the shoot apical meristem, a developmental dynamo. Develop Biol 2010, 341:95-113.

39. Baucher M, Jaziri El M, Vandeputte O: From primary to secondary growth: origin and development of the vascular system. J Expl Bot 2007, 58:3485-50I.

40. Lau OS, Bergmann DC: Stomatal development: a plant's perspective on cell polarity, cell fate transitions and intercellular communication. Development 2012, 139:3683-92.

4I. Richardson LGL, Torii KU: Take a deep breath: peptide signalling in stomatal patterning and differentiation. J Exper Bot 2013, 64:5243-51.

42. Le J, Liu X-G, Yang K-Z, Chen X-L, Zou J-J, Wang H-Z, Wang M, Vanneste S, Morita M, Tasaka M, Ding Z-J, Friml J, Beeckman T, Sack F: Auxin transport and activity regulate stomatal patterning and development. Nat Communs 2014, 5:3090.

43. Aaronson DS: A Road Map for Those Who Don't Know JAKSTAT. Science 2002, 296: 1653-5.

44. Wigge PA, Weigel D: Arabidopsis genome: life without notch. Curr Biol 200I, II:RI I 2-4.

45. Bergmann DC: Stomatal Development and Pattern Controlled by a MAPKK Kinase. Science 2004, 304: 1494-7.

\section{FlOOOPrime} RECOMMENDED

46. Cristina M, Petersen M, Mundy J: Mitogen-Activated Protein Kinase Signaling in Plants. Annu Rev Plant Biol 2010, 61:621-49.

47. Robinson $S$, Barbier de Reuille $P$, Chan J, Bergmann D, Prusinkiewicz $P$, Coen E: Generation of Spatial Patterns Through Cell Polarity Switching. Science 20II, 333:1436-40.

\section{FlOOOPrime} RECOMMENDED

48. Klein AM, Simons BD: Universal patterns of stem cell fate in cycling adult tissues. Development 20II, I38:3103-II.

\section{FlOOOPrime
RECOMMENDED}

49. Jaenisch R, Young R: Stem Cells, the Molecular Circuitry of Pluripotency and Nuclear Reprogramming. Cell 2008, I32:567-82.

50. Araki R, Hoki $Y$, Uda M, Nakamura M, Jincho $Y$, Tamura C, Sunayama M, Ando S, Sugiura M, Yoshida MA, Kasama Y, Abe M: Crucial role of c-Myc in the generation of induced pluripotent stem cells. STEM CELLS 201।, 29:1362-70.

\section{FlOOOPrime}

\section{RECOMMENDED}

5I. Makkena S, Lamb RS: 2013-makkena-The bHLH transcription factor SPATULA regulates root growth by controlling the size of the root meristem. BMC Plant Biol 2013, 13:I.

\section{FlOOOPrime}

RECOMMENDED

52. Yang F, Wang Q, Schmitz G, Müller D, Theres K: The bHLH protein ROX acts in concert with RAXI and LAS to modulate axillary meristem formation in Arabidopsis. Plant J 20I2, 7I:6I-70.

\section{FlOOOPrime}

\section{RECOMMENDED}

53. Ohashi-Ito K, Bergmann DC: Regulation of the Arabidopsis root vascular initial population by LONESOME HIGHWAY. Development 2007, 134:2959-68.

54. De Rybel B, Möller B, Yoshida S, Grabowicz I, de Reuille PB, Boeren S, Smith RS, Borst JW, Weijers D: A bHLH Complex Controls 
Embryonic Vascular Tissue Establishment and Indeterminate Growth in Arabidopsis. Develop Cell 2013, 24:426-37.

\section{FIOOOPrime}

55. Lai HC, Meredith DM, Johnson JE: bHLH Factors in Neurogenesis and Neuronal Subtype Specification. In Patterning and cell specification in the developing CNS and PNS. Ist edition. Edited by Rubenstein J and Rakic P. Elsevier Inc; 2013:333-54.

56. Kageyama R, Ohtsuka T, Hatakeyama J, Ohsawa R: Roles of bHLH genes in neural stem cell differentiation. Exp Cell Res 2005, 306:343-8.

57. Curtis DJ, Salmon JM, Pimanda JE: Concise Review: Blood Relatives: Formation and regulation of hematopoietic stem cells by the basic helix-loop-helix transcription factors stem cell leukemia and lymphoblastic leukemia-derived sequence I. STEM CELLS 2012, 30:1053-8.

58. Conway SJ, Firulli B, Firulli AB: A bHLH Code for Cardiac Morphogenesis. Pediatr Cardiol 2009, 3 I:3 I8-24.

59. van der Flier LG, Clevers H: Stem Cells, Self-Renewal, and Differentiation in the Intestinal Epithelium. Annu Rev Physiol 2009, 7I:24I-60.

60. Habener JF, Kemp DM, Thomas MK: Minireview: Transcriptional Regulation in Pancreatic Development. Endocrinology 2005, | 46: | 025-34.

61. MacAlister CA, Ohashi-Ito K, Bergmann DC: Transcription factor control of asymmetric cell divisions that establish the stomatal lineage. Nature 2006, 445:537-40.

\section{FlOOOPrime \\ RECOMMENDED}

62. Pillitteri LJ, Sloan DB, Bogenschutz NL, Torii KU: Termination of asymmetric cell division and differentiation of stomata. Nature 2006, 445:501-5.

\section{FlOOOPrime} RECOMMENDED

63. Ohashi-Ito K, Bergmann DC: Arabidopsis FAMA Controls the Final Proliferation/Differentiation Switch during Stomatal Development. The Plant Cell 2006, I 8:2493-505.

\section{FIOOOPrime}

\section{RECOMMENDED}

64. Kanaoka MM, Pillitteri LJ, Fujii H, Yoshida Y, Bogenschutz NL, Takabayashi J, Zhu JK, Torii KU: SCREAM/ICEI and SCREAM2 Specify Three Cell-State Transitional Steps Leading to Arabidopsis Stomatal Differentiation. Plant Cell 2008, 20: I775-85.

\section{FlOOOPrime}

\section{RECOMMENDED}

65. Bentzinger CF, Wang YX, Rudnicki MA: Building Muscle: Molecular Regulation of Myogenesis. Cold Spring Harb Perspect Biol 2012, 4:a008342.

66. Buckingham M, Rigby PWJ: Gene Regulatory Networks and Transcriptional Mechanisms that Control Myogenesis. Develop Cell 20I4, 28:225-38.

67. Singh K, Dilworth FJ: Differential modulation of cell cycle progression distinguishes members of the myogenic regulatory factor family of transcription factors. FEBS J 2013, 280:399|-4003.

68. Chang NC, Rudnicki MA: Satellite Cells: the Architects of Skeletal Muscle. In Current Topics in Developmental Biology. Volume 107. Ist edition. Edited by Rendl M. Elsevier Inc; 2014:161-81.

69. Guasconi V, Puri PL: Chromatin: the interface between extrinsic cues and the epigenetic regulation of muscle regeneration. Trends Cell Biol 2009, I 9:286-94.
70. Bharathy N, Ling BMT, Taneja R: Epigenetic Regulation of Skeletal Muscle Development and Differentiation. In "Epigenetics: Development and Disease. Edited by Kundu TK. Dordrecht: Springer Netherlands; 2012:139-50.

7I. Bezhani S, Winter C, Hershman S, Wagner JD, Kennedy JF, Kwon CS, Pfluger J, Su Y, Wagner D: Unique, Shared, and Redundant Roles for the Arabidopsis SWI/SNF Chromatin Remodeling ATPases BRAHMA and SPLAYED. Plant Cell 2007, 19:403-16.

\section{FlOOOPrime}

RECOMMENDED

72. Sung ZR, Belachew A, Shunong B, Bertrand-Garcia R: EMF, an Arabidopsis Gene Required for Vegetative Shoot Development. Science 1992, 258: I645-7.

73. Yoshida N, Yanai Y, Chen L, Kato Y, Hiratsuka J, Miwa T, Sung ZR, Takahashi S: EMBRYONIC FLOWER2, a novel polycomb group protein homolog, mediates shoot development and flowering in Arabidopsis. Plant Cell 200I, 13:247I-8I.

\section{FlOOOPrime}

\section{RECOMMENDED}

74. Borghi L, Gutzat R, Futterer J, Laizet Y, Hennig L, Gruissem W: Arabidopsis RETINOBLASTOMA-RELATED Is Required for Stem Cell Maintenance, Cell Differentiation, and Lateral Organ Production. Plant Cell 2010, 22:1792-8II.

75. Wildwater M, Campilho A, Perez-Perez JM, Heidstra R, Blilou I, Korthout H, Chatterjee J, Mariconti L, Gruissem W, Scheres B: The RETINOBLASTOMA-RELATED Gene Regulates Stem Cell Maintenance in Arabidopsis Roots. Cell 2005, I 23:1337-49.

\section{FlOOOPrime}

\section{RECOMMENDED}

76. Deato MDE, Marr MT, Sottero T, Inouye C, Hu P, Tjian R: MyoD Targets TAF3/TRF3 to Activate Myogenin Transcription. Mol Cell 2008, 32:96-105.

77. de Mendoza A, Sebé-Pedrós A, Šestak MS, Matejcic M, Torruella G, Domazet-Loso T, Ruiz-Trillo I: Transcription factor evolution in eukaryotes and the assembly of the regulatory toolkit in multicellular lineages. Proc Natl Acad Sci U S A 20 I 3, I I 0:E4858-66.

\section{FIOOOPrime
RECOMMENDED}

78. MacAlister CA, Bergmann DC: Sequence and function of basic helix-loop-helix proteins required for stomatal development in Arabidopsis are deeply conserved in land plants. Evol Develop 2011, 13:182-92

79. Ran J-H, Shen T-T, Liu W-J, Wang X-Q: Evolution of the bHLH Genes Involved in Stomatal Development: Implications for the Expansion of Developmental Complexity of Stomata in Land Plants. PLoS ONE 2013, 8:e78997.

80. Atchley WR, Fitch WM, Bronner-Fraser M: Molecular evolution of the MyoD family of transcription factors. Proc Natl Acad Sci USA |994, 9 I: | I522-6.

81. Ozernyuk ND, Myuge NS: Evolutional principles of homology in regulatory genes of myogenesis. Biol Bull Russ Acad Sci 2012, 39:316-22.

82. Rai M, Nongthomba U, Grounds MD: Skeletal Muscle Degeneration and Regeneration in Mice and Flies. In Current Topics in Developmental Biology. Volume 108. Ist edition. Edited by Galliot B. Elsevier Inc; 2014:247-8I.

83. Aboobaker AA: Planarian stem cells: a simple paradigm for regeneration. Trends Cell Biol 20 II, 2 I:304-II. 